\title{
Sensitivity of static energy meter reading errors to changes in non-sinusoidal load conditions
}

\author{
Z. Marais ${ }^{1,2}$, H.E. van den Brom ${ }^{1}$, G. Rietveld ${ }^{1}$, R. van Leeuwen ${ }^{1}$, D. Hoogenboom ${ }^{1}$, J. Rens ${ }^{2}$ \\ ${ }^{1}$ Van Swinden Laboratory, Delft, The Netherlands; ${ }^{2}$ North West University, Potchefstroom, South Africa.
}

\begin{abstract}
Previous studies regarding static energy meter errors under non-sinusoidal load conditions have shown that these meters can produce erroneous readings. This paper describes an investigation done using loads consisting of a commercial lighting dimmer in combination with either a resistive heater or an array of various energy-saving lamps. Dimmer impedance and phase firing angle were gradually adjusted to change load conditions. Several meters showed dramatic variations in metering error under different load conditions. In the most extreme case, metering errors ranged from five times the energy consumed by the load to registering almost no energy. Though perhaps not typically found in households, the load combinations used in this study were able to highlight sensitivities of different static energy meters to changes in load conditions.
\end{abstract}

Keywords - static energy meter; metering error; electromagnetic interference; accuracy; impedance; phase firing angle.

\section{BACKGROUND}

\section{A. Static energy meter reading errors}

Some household static energy meters are known to give erroneous energy readings when exposed to certain extremely non-sinusoidal current signals. Studies conducted by the University of Twente (UTwente) highlight the fact that energy meters can produce considerable errors when exposed to certain types of interference [1], [2]. These tests have been reproduced by Van Swinden Laboratory (VSL) on a larger variety of meters with similar results [3]. In these investigations, resistive and non-linear loads were used in combination with a phase firing dimmer. Meters from different manufacturers and meters using different current sensor technologies appear to produce errors under a range of conditions, with meters employing Rogowski coils for current measurements being the most susceptible.

The magnitude of the energy metering error depends on external factors, such as load current amplitude and rise time of the current variations [3]. Little information on the exact mechanisms causing these errors is available, as details of the internal working principle of static energy meters is kept confidential by manufacturers. The investigation documented in this paper attempts to characterize static energy meter reading errors under different load conditions.

This work is carried out within the EMPIR project 17NRM02 MeterEMI which has received funding from the EMPIR programme co-financed by the Participating States and from the European Union's Horizon 2020 research and innovation programme.

\section{B. Conducted electromagnetic interference of household loads}

Compact fluorescent lamps (CFL) and light emitting diode (LED) lamps make use of rectifiers and switch-mode converters to convert the grid voltage to required levels. Non-linear operation of the electronic components results in harmonic currents and other unwanted high frequency emissions [4].

To improve the current waveform, energy saving lamps implement various forms of power factor correction, smoothing out the current drawn by the lamps into a shape better resembling the applied voltage waveform. This power factor correction reduces harmonic emissions, improves current crest factor and may be required for electromagnetic compatibility compliance.

The shape of the current waveform withdrawn by an energysaving lamp depends on the type of power factor correction applied [5]. It is also sensitive to the impedance of the supply system, the voltage total harmonic distortion and to the type of other loads connected onto the same network [6].

European standards, such as the IEC 61000-3-2 [7], require household loads up to $16 \mathrm{~A}$ per phase to comply to harmonic emission limits that depend on the type of load and load size. These limits are in place to contain voltage waveform distortion. Electronic loads that consume less than $75 \mathrm{~W}$ (excluding lighting equipment) are excluded from these harmonic limits, as their impact on voltage and current distortion is assumed to be negligible due to low power consumption. However, harmonic emissions resulting from multiple poorly compensated rectified loads are often in phase [8]. If a sufficient number of these loads are present, then the resulting harmonic emissions, fast transients and high peak currents could negatively impact energy meter accuracy. In addition, electronic loads with high switching frequencies, and devices that employ power line communication also produce $2 \mathrm{kHz}$ to $150 \mathrm{kHz}$ emissions that could also influence accuracy of static energy meters [4].

\section{INVESTIGATION}

\section{A. Aim of the investigation}

Previous work has shown a correlation between loads with high peak currents or fast current transients and metering errors in static energy meters [3]. Sensitivity of non-linear load characteristics to network conditions implies that the same load connected under different supply conditions could result in different static energy meter errors. Loads replicated under laboratory conditions, or identical loads connected to different power sources may not be able to replicate these errors, which is concerning for meter compliance tests based on replicated load 


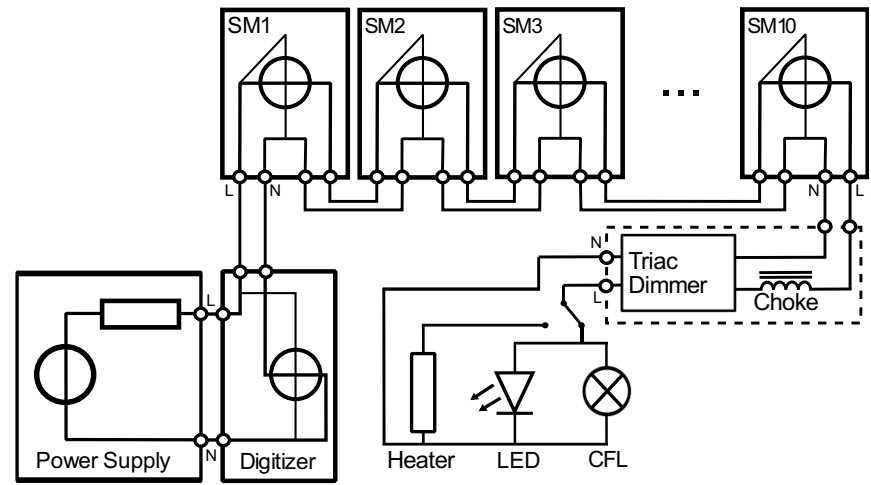

Fig. 1. VSL household energy meter test setup for non-linear loads

conditions. To investigate the sensitivity of meter errors to load conditions, the input impedance of a dimmed load was systematically varied. The impact of dimmer phase firing angle and the impact of additional load current on metering error was also investigated in separate tests.

\section{B. Test Setup}

The VSL test setup for evaluating EMI effects of non-linear loads on energy meters [3] is based on the test setup used in the UTwente studies [1], [2]. A schematic of this setup is shown in Fig. 1. A series of static energy meters measure energy consumed by a non-linear load when supplied by a $230 \mathrm{~V}, 50 \mathrm{~Hz}$ sinusoidal voltage from a $4.5 \mathrm{kVA}$ precision AC power supply with a steady-state output impedance of $7 \mathrm{~m} \Omega$.

Measurements are benchmarked against a wideband reference energy meter, which consists of a wideband digitizer sampling at $1 \mathrm{MSa} / \mathrm{s}$ [9] using a wideband shunt [10] for current measurement and a wideband voltage divider. Uncertainty of the measurement setup is less than $0.02 \%$ for voltages and currents at $50 \mathrm{~Hz}$ and less than $0.5 \%$ for the non-sinusoidal waveforms used in this investigation [3].

The static energy meters emit a pulse of light each time a preset number of watt hours is recorded. These pulses are logged using optical sensors and can be counted to calculate the accumulated watt hours measured by each meter. Pulse measurements are time stamped and the accumulated energy compared to the energy measured by the reference meter (digitizer) within the same period. The resulting energy metering error becomes apparent within minutes.

\section{Static energy meters tested}

Ten different household static energy meters of accuracy class A were selected. These meters come from various manufacturers and a number of them have produced erroneous results in previous studies. They make use of different current sensing technologies including Rogowski coils (4), Hall effect sensors (2), shunt resistors (2) and current transformers (2). To ensure that tests are conducted under comparable load conditions, all ten meters are measured simultaneously under the same test conditions.

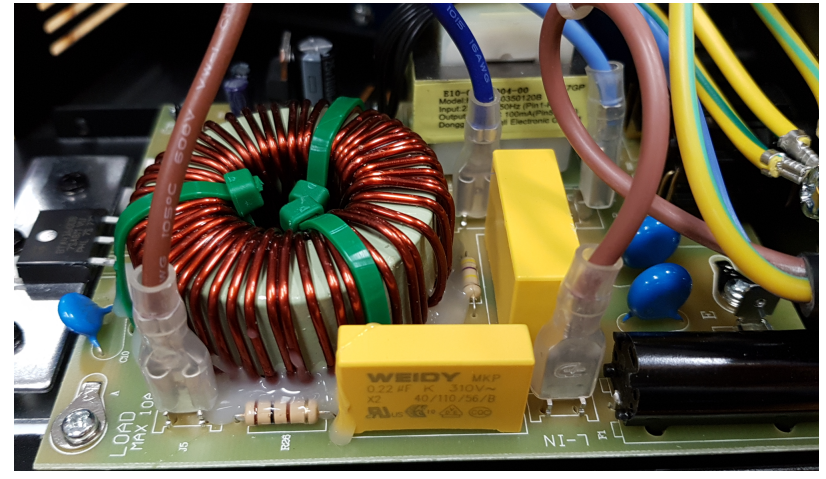

Fig. 2. Photograph of the dimmer choke inductor

\section{Energy metering error}

Metering error was defined as the difference between the measurements of the static meter energy $E_{M U T}$ and the reference meter energy $E_{r e f}$. Since the static meters do not register energy consumed by the meter itself, $E_{r e f}$ is corrected for static meter energy consumption by subtracting the energy consumed by each subsequent energy meter (typically between $1 \mathrm{~W}$ and $2 \mathrm{~W}$ per meter) from the energy measured by the reference instrument. This results in an average meter reading error $\varepsilon_{M U T}$ over the measurement period:

$$
\varepsilon_{M U T}(n)=\frac{E_{M U T}(n)-E_{r e f}(n)}{E_{r e f}(n)} \times 100 \%
$$

Where $n$ denotes the meter number and $E_{\text {ref }}(n)$ the reference energy corrected for meter energy consumption.

\section{E. Load}

A leading-edge phase-firing dimmer connected to either a non-linear load of multiple energy saving lamps (CFL and LED) or an $800 \mathrm{~W}$ heater (resistive load) was used. These load combinations are similar to those previously used in the UTwente and VSL studies [1], [3] and although not typically found in European households, are proven to cause static energy meter reading errors.

The dimmer used is a commercially available leading-edge phase-firing dimmer for incandescent lamps, rated at $10 \mathrm{~A}$. Internal switching is done by a TRIAC and the input is filtered by a $373 \mu \mathrm{H}$ inductor shown in Fig. 2 . Firing angle is digitally controlled and accurate to within $1^{\circ}$ of the $50 \mathrm{~Hz}$ phase angle.

For the first set of tests, supply impedance was varied by changing the filter (also referred to as a choke) inductance. The number of windings around the core was systematically reduced which resulted in measured inductances of $373 \mu \mathrm{H}, 221 \mu \mathrm{H}$, $147 \mu \mathrm{H}, 113 \mu \mathrm{H}, 86 \mu \mathrm{H}, 56 \mu \mathrm{H}$ and $35 \mu \mathrm{H}$. After this, the inductor was removed completely.

For these tests, the dimmer phase-firing angle was set to $110^{\circ}$ as this phase firing angle lies between $90^{\circ}$ (50\% phase firing) and $122^{\circ}$ degrees, where insufficient energy causes the CFL and LED load combination to visually flicker. The same dimmer setting was used for both the resistive and non-linear load to 


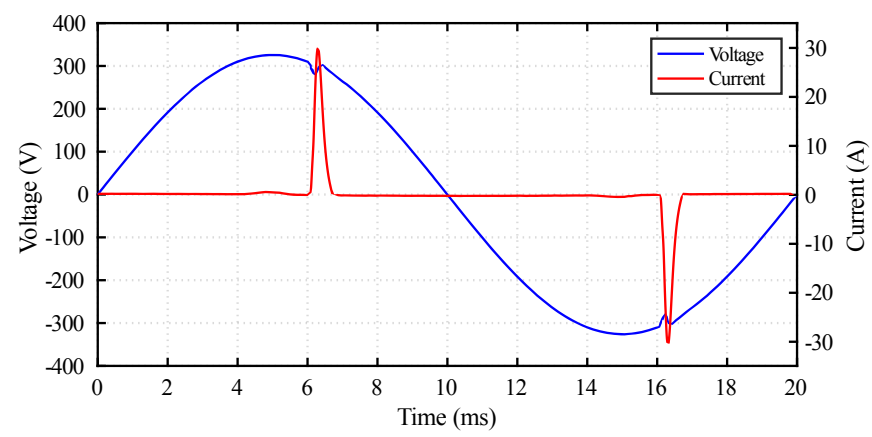

(a)

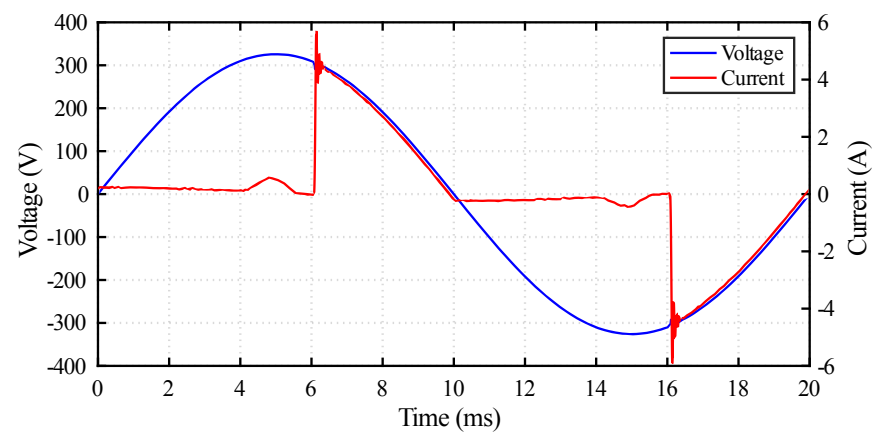

(b)

Fig. 3. Voltage and current waveforms for (a) $110^{\circ}$ dimmed CFL + LED lamps and (b) $110^{\circ}$ dimmed heater

isolate the effect of inductance from phase firing angle. At this dimmer setting, both load combinations consume approximately $270 \mathrm{~W}$ of active power.

A second set of tests were conducted using different phase firing angles for the CFL and LED load combination at a fixed inductance of $56 \mu \mathrm{H}$. These tests were then repeated using a similar dimmer with a choke inductance of $26 \mu \mathrm{H}$ as additional comparison.

\section{F. Load waveforms}

Voltage and current waveforms of all tests were recorded by the wideband reference energy meter. This section illustrates how changes in load parameters changes the load current waveform.

Fig. 3(a) shows voltage and current waveforms for a CFL and LED load and in Fig 3(b) for a resistive load when the firing angle is set to approximately $110^{\circ}$. With this dimmer setting, the lamp current has a high peak and high crest factor. The resistive load current linearly relates to the dimmed voltage but oscillates at a higher frequency after switching. Current drawn due to the power consumption of the static energy meters is centered around the voltage peaks, as can be seen in Fig. 3(a) and Fig. 3(b). This additional power consumption is small compared to the connected load and has negligible influence on the calculated meter errors after correction.

Changes in dimmer inductance resulted in changes in load current characteristics for the non-linear lamp combination, even when not being dimmed. Fig. 4 shows the current waveforms of the undimmed CLF and LED load for three dimmer choke inductance levels $(373 \mu \mathrm{H}, 113 \mu \mathrm{H}$ and $0 \mu \mathrm{H})$. The change in

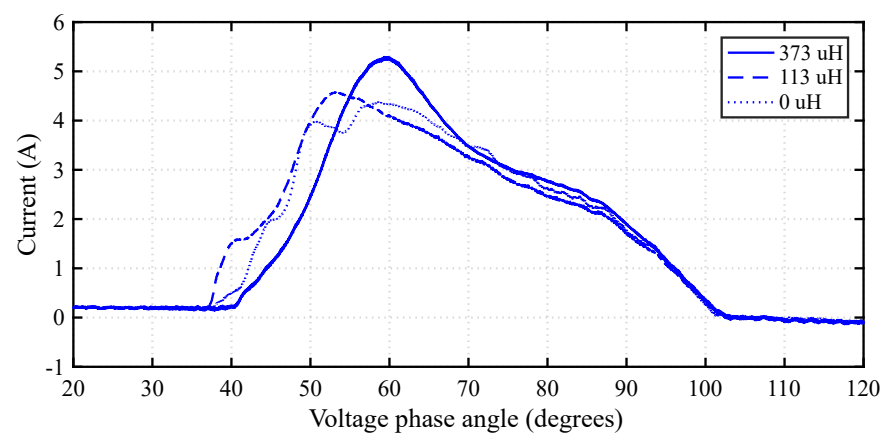

Fig. 4. Undimmed CFL + LED load waveform at different dimmer inductances

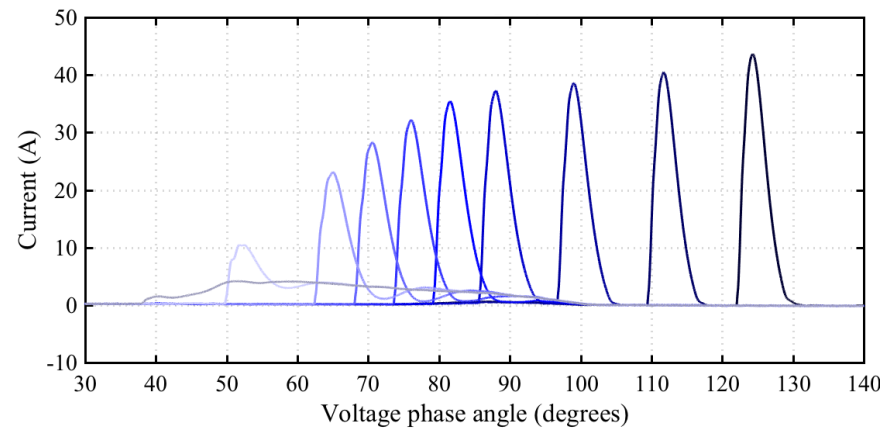

Fig. 5. CFL and LED current waveforms at dimmer phase firing angles between $35^{\circ}$ and $122^{\circ}$ with $56 \mu \mathrm{H}$ dimmer inductance

waveform shape highlights the sensitivity of rectified non-linear loads to network conditions, as emulated with the changes to dimmer inductance.

Waveform characteristics are also influenced by the phase firing angle of the dimmer. Peak current amplitude increases as phase firing angle is increased, since the control circuits of the lamps attempt to regulate lumen production by keeping power consumption constant. Fig. 5 shows the load current of various firing angles for tests conducted with a dimmer choke inductance of $56 \mu \mathrm{H}$. Due to the dimming applied, the power factor correction of the individual lamps becomes ineffective. Once the firing angle is low enough that the load operates under grid voltage conditions (undimmed) for at least a part of the cycle where the load normally draws current, this negative effect is reduced and peak current decreases. At choke inductances less than $56 \mu \mathrm{H}$, the dimmer is unable to energize the CFL and LED combined load and only provides an undimmed voltage as output. For the resistive load, the dimmer functions for all inductor values and with the choke inductor removed.

Load currents of the CFL and LED lamp combination when dimmed at a phase firing angle of approximately $110^{\circ}$ and connected with different dimmer choke inductances are shown in Fig. 6(a). Peak current increases and rise time decreases when reducing supply impedance. Fig. 6(b) shows the differential current of the same waveform. Higher levels in $d I / d t$ are present and higher frequency currents increase in amplitude, which becomes notable for frequencies above approximately $1 \mathrm{kHz}$ as shown in Fig. 6(c).

Similar to the CFL and LED load, the dimmed resistive load waveforms shown in Fig. 7 have increased peak current and a 


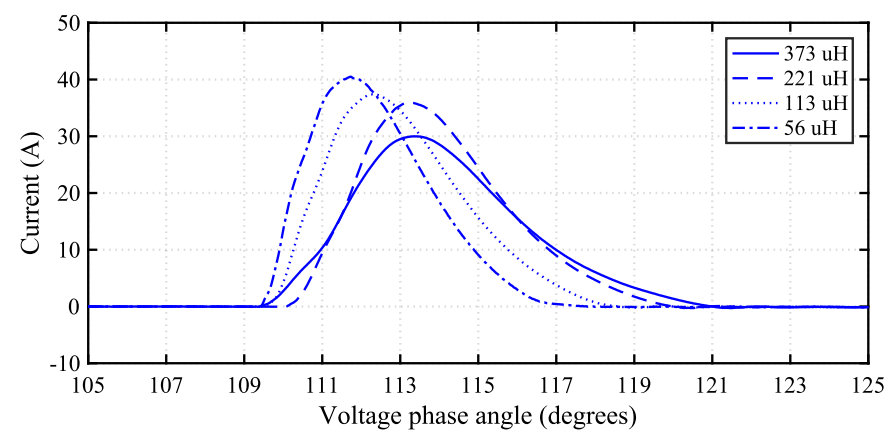

(a)

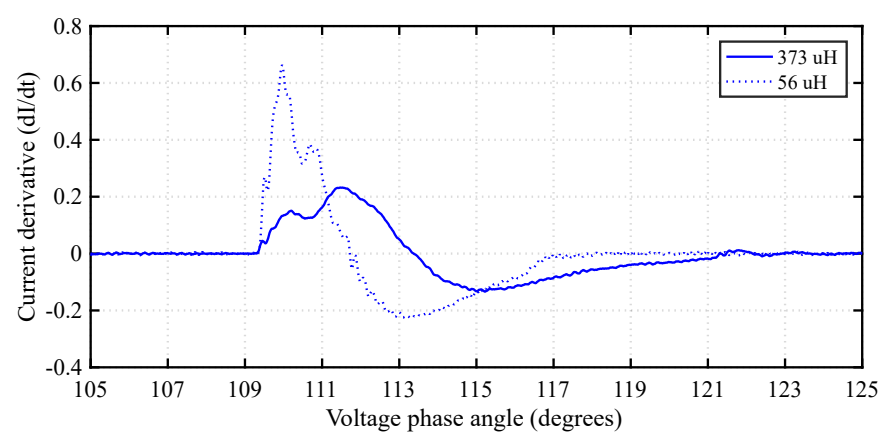

(b)

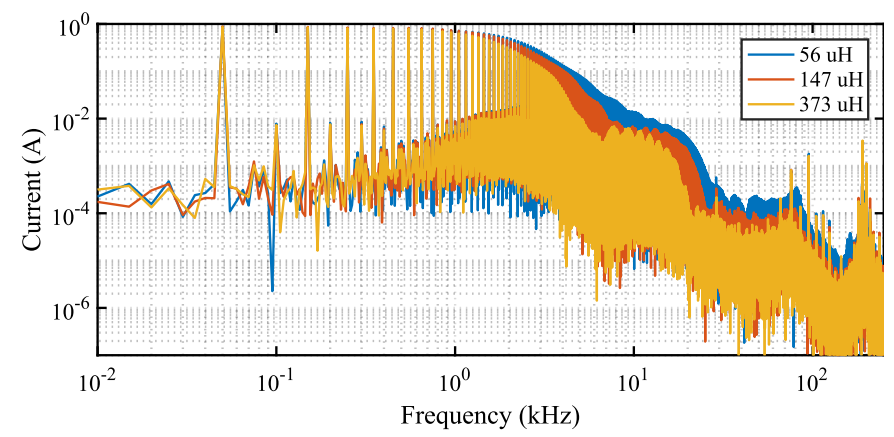

(c)

Fig. 6. Dimmed CFL+LED load current (a), current derivative (b) and FFTs (c) at different dimmer inductances and a $110^{\circ}$ phase firing angle

shorter rise time when reducing the supply inductance. Peak current amplitude and maximum $d I / d t$ are lower than that of the dimmed CFL and LED lamp combination. An increase in higher frequency currents is apparent above approximately $10 \mathrm{kHz}$. It is expected that the dimmed CFL and LED load combination will cause greater energy reading errors than the resistive load combination.

\section{TEST RESUltS}

\section{A. Meter reading error for different impedances}

Ten static energy meters where grouped based on the current sensing technology employed. Fig. 8(a) shows the static meter error for a range of dimmer choke inductance values for the resistive load and in Fig 8(b) for the CFL and LED lamps, both dimmed at a firing angle of $110^{\circ}$.

From Fig. 8(a) it can be observed that with the dimmed resistive load connected, two of the Rogowski-based energy

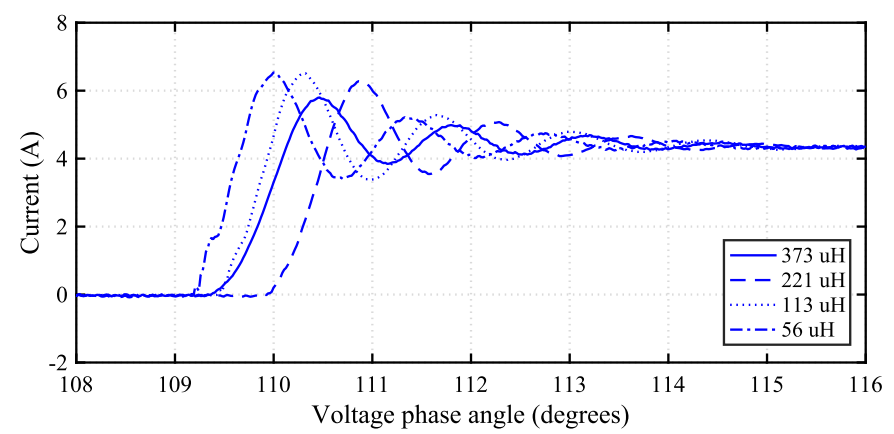

(a)

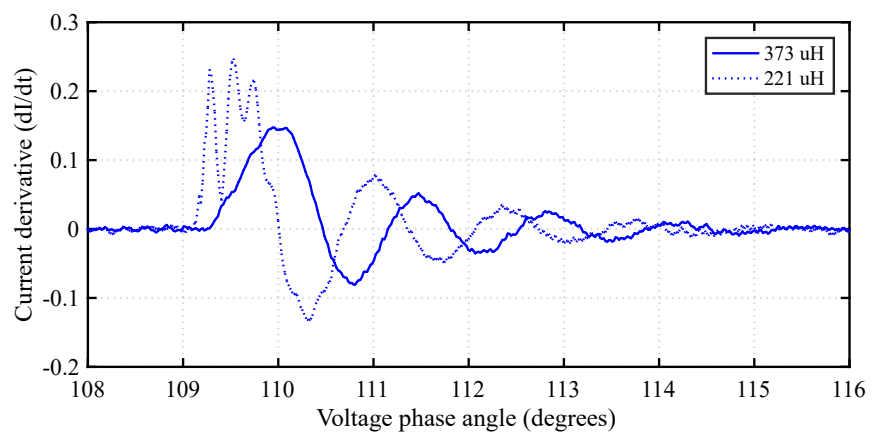

(b)

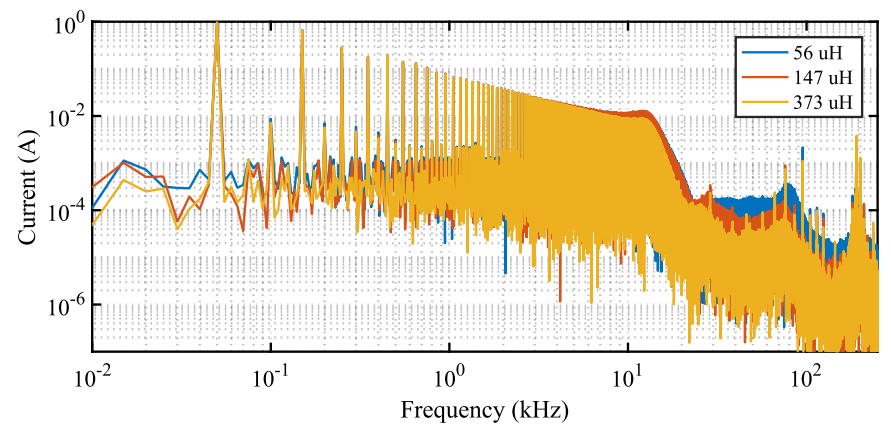

(c)

Fig. 7. Dimmed heater load current (a), current derivative (b) and FFTs (c) at different dimmer inductances and a $110^{\circ}$ phase firing angle

meters have erroneous energy readings (Meter 3 and Meter 4). This error increases as dimmer impedance is reduced. The effect of impedance on metering error of the rest of the energy meters is negligible when connected to the dimmed resistive load for all inductance values investigated.

The dimmed CFL and LED load resulted in large positive or negative errors for eight of the ten static meters selected in this study, as shown in Fig. 8(b). Both energy meters using CTs (Meter 5 and Meter 6) measure energy up to $33 \%$ less than the reference value. Hall effect meters (Meter 7 and Meter 8) are unaffected by the change in supply impedance. One shunt meter (Meter 9) recorded less than $20 \%$ of energy consumed $(80 \%$ error) at all dimmer inductances of $221 \mu \mathrm{H}$ or lower, while the other shunt meter (Meter 10) was unaffected. Two Rogowski meters (Meter 1 and Meter 2) measured increasingly incorrect as supply impedance is reduced. A maximum error of $210 \%$ was found at Meter 1. An active power measurement error of almost $300 \mathrm{~W}$. Metering error for Rogowski coil energy meters are 


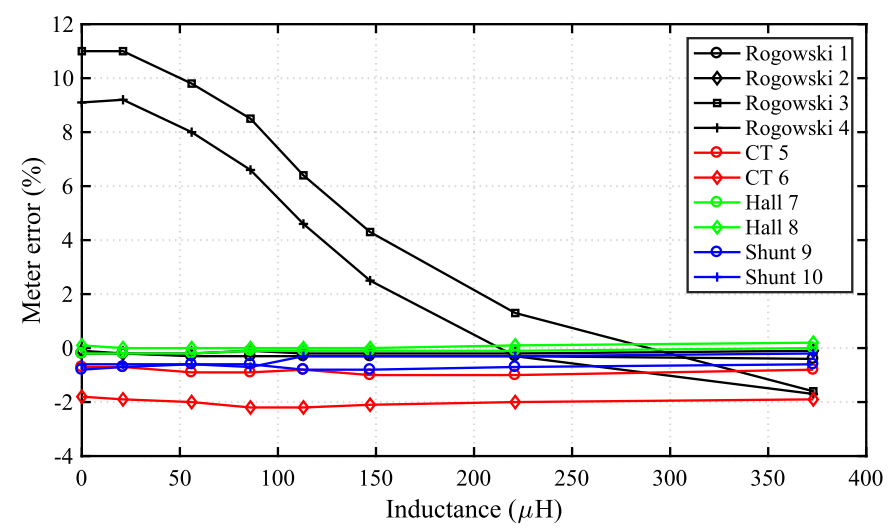

(a)

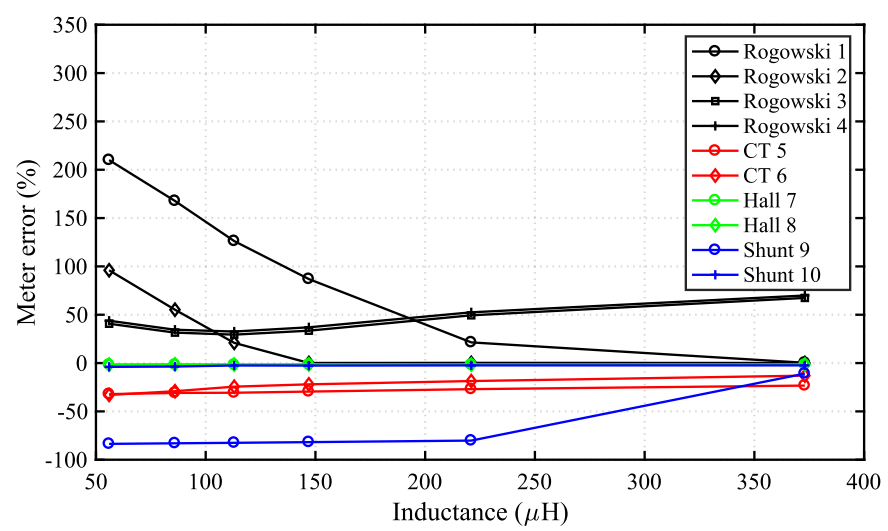

(b)

Fig. 8. Effect of dimmer inductance on static meter error for (a) resistive load and (b) CFL + LED lamps at a phase firing angle of $110^{\circ}$

expected to increase at lower inductance levels for the dimmed CFL and LED load.

\section{B. Effect of phase firing angle on meter error}

Fig. 5 shows that the shape and amplitude of the current waveform changes significantly as the dimmer firing angle is varied. The impact of firing angle on metering errors was investigated using the CFL and LED load. As an additional comparison, the test was repeated on a second dimmer with a modified choke inductance of $26 \mu \mathrm{H}$. Fig. 9 compares the two test results.

Metering error trends for both dimmers are similar, but errors are more extreme for the second dimmer which has a smaller choke inductance. Errors also become larger as firing angle increases. The largest errors were obtained at a $122^{\circ}$ firing angle for the energy meters using Rogowski coils. A measurement error in energy of $400 \%$ was obtained by Rogowski meter 4 at a firing angle of $122^{\circ}$. This corresponds to an average error in active power measurement of $1350 \mathrm{~W}$, five times the actual value for active power consumed in the load.

Metering errors reach a minimum for Rogowski meters 1 and 2 at a firing angle of approximately $90^{\circ}$, which is also the phase firing angle where compliance tests for phase fired waveforms

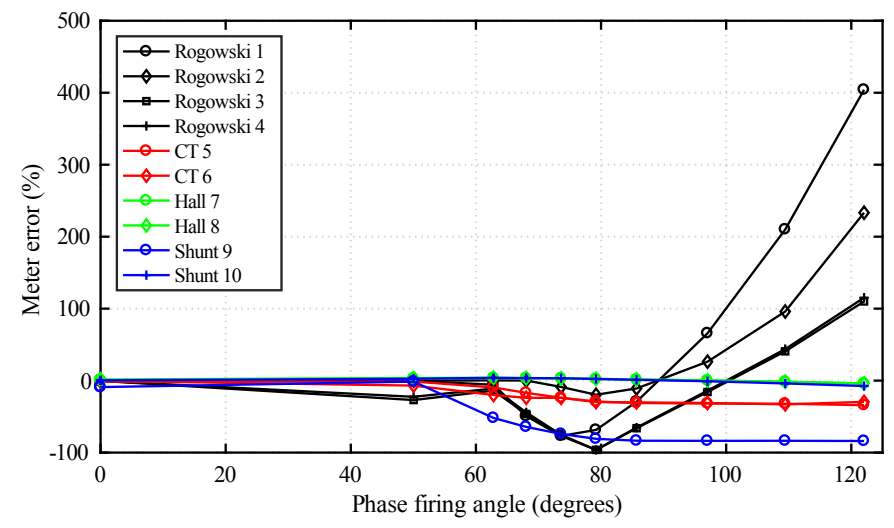

(a)

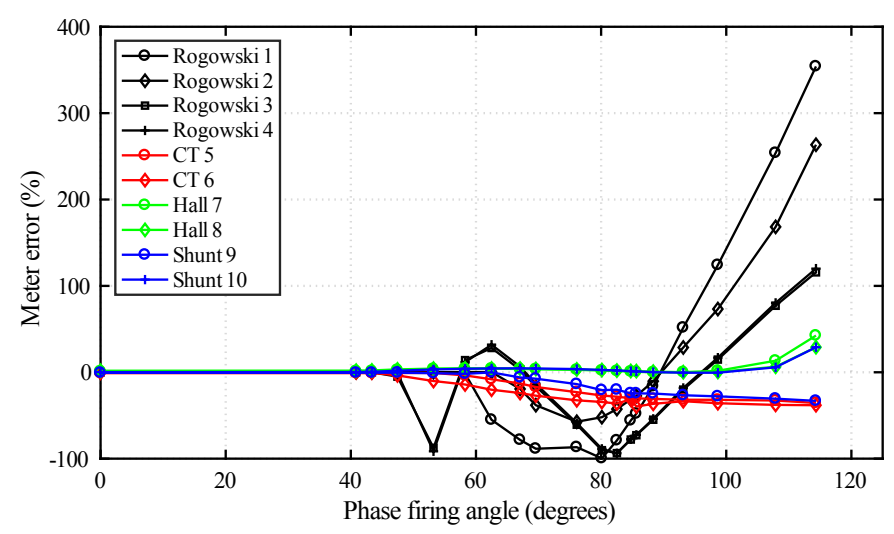

(b)

Fig. 9. Effect of dimmer phase firing angles on static meter error for two different dimmers with a choke inductance of (a) $56 \mathrm{uH}$ and (b) $26 \mathrm{uH}$

are conducted [11]. Rogowski meters 3 and 4 have near zero error at a firing angle of approximately $100^{\circ}$. At smaller firing angles (less dimming), the error changes from positive to negative until no energy is registered near $80^{\circ}$. For the second

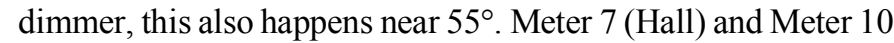
(shunt) only start to show metering error at firing angles larger than $100^{\circ}$ when connected to the second dimmer. All other meters produced negative metering errors at firing angles larger than $40^{\circ}$, with errors increasing as firing angle is increased.

\section{Metering error with and without additional resistive load}

An $800 \mathrm{~W}$ resistive load (without dimmer) was connected in parallel with the dimmed CFL and LED load of approximately $270 \mathrm{~W}$. To compare meter errors across power levels, the average power registered by each meter over the measurement time was calculated. Table I shows the difference in error for each meter (expressed in watt) when measured without and with the additional resistive load.

Minimal difference in metering error is seen in energy meters using Rogowski sensors. The energy meters using current transformers are the most affected by additional load. Energy meters 8 and 9 using Hall effect sensors and energy meter 10 using a shunt current sensor show negligible change in metering error. 
TABLE I. METER ERRORS WITH ADDITIONAL LOAD

\begin{tabular}{|c|l|c|c|c|}
\hline Meter & Sensor type & $\begin{array}{c}\text { Error without } \\
\text { heater }(\boldsymbol{W})\end{array}$ & $\begin{array}{c}\text { Error with } \\
\text { heater }(\boldsymbol{W})\end{array}$ & $\begin{array}{c}\text { Difference } \\
(\boldsymbol{W})\end{array}$ \\
\hline 1 & Rogowski & 689 & 708 & 19 \\
\hline 2 & Rogowski & 229 & 247 & 18 \\
\hline 3 & Rogowski & 173 & 153 & -20 \\
\hline 4 & Rogowski & 181 & 163 & -18 \\
\hline 5 & CT & -76 & -104 & -28 \\
\hline 6 & CT & -58 & -11 & 47 \\
\hline 7 & Hall & -8 & -10 & -2 \\
\hline 8 & Hall & -8 & -9 & -1 \\
\hline 9 & Shunt & -63 & -86 & -23 \\
\hline 10 & Shunt & -15 & -15 & 0 \\
\hline
\end{tabular}

In practice, multiple linear and non-linear loads are connected simultaneously. If the combination of loads causes large peak currents or fast current transients similar to those seen in this investigation, energy metering errors could be present regardless of the linear portion of the load.

\section{CONCLUSION}

The energy metering errors of ten different static energy meters with four different current sensing techniques were characterized under different load conditions. The meters were selected from a batch of more than 50 different meters, based on the metering errors they showed in previous studies. By systematically varying the test conditions, more insight has been gained on the behavior of the metering errors.

A reduction in impedance connected to the load resulted in more extreme errors. For the most extreme test conditions, meters from all four different current sensing techniques showed metering errors. At the impedance levels investigated, the dimmed CFL + LED load produced large errors, whereas the dimmed resistive load only affected the accuracy of two meters employing similar current sensor technologies at the phase firing angle investigated. The metering errors of affected meters connected to a specific load can be positive, negative or negligible depending on the meter technology and phase firing angle of the dimmer. Generally, an additional linear load is measured correctly, also in the presence of conducted EMI causing meter errors.

The high sensitivity of the energy metering errors to test conditions poses a challenge for the reproducibility of this type of meter accuracy tests. For reproduceable results, test conditions should be well documented, and ideally, voltage and current waveforms should be generated using amplifiers to eliminate any variation in loading conditions.

\section{REFERENCES}

[1] F. Leferink, C. Keyer, and A. Melentjev, "Static energy meter errors caused by conducted electromagnetic interference", IEEE Electromagnetic Compatability Magazine., vol. 5, no. 4, 2016, pp. 49-55.

[2] F. Leferink, C. Keyer and A. Melentjev, "Runaway energy meters due to conducted electromagnetic interference," 2016 International Symposium on Electromagnetic Compatibility - EMC EUROPE, Wroclaw, 2016, pp. $172-175$.

[3] G. Rietveld, D. Hoogenboom and M. Acanski, "Conducted EMI Causing Error Readings of Static Electricity Meters," 2018 Conference on Precision Electromagnetic Measurements (CPEM 2018), Paris, 2018, pp. 1-2.

[4] CENELEC SC 205A Report: Electromagnetic Interference between Electrical Equipment / Systems in the Frequency Range below $150 \mathrm{kHz}$, 3rd edition, 2015.

[5] A. M. Blanco, M. Gupta, A. G. De Castro, S. Rönnberg, and J. Meyer, "Impact of flat-top voltage waveform distortion on harmonic current emission and summation of electronic household appliances", Renewable Energy and Power Quality Journal, vol. 1, no. 16, 2018, pp. 698-703.

[6] A. Gil-De-Castro, R. Medina-Gracia, S. K. Ronnberg, A. M. Blanco and J. Meyer, "Differences in the performance between CFL and LED lamps under different voltage distortions", 2018 18th International Conference on Harmonics and Quality of Power (ICHQP), Ljubljana, 2018, pp. 1-6.

[7] IEC 61000-3-2: Electromagnetic compatibility (EMC) - Part 3-2: Limits - Limits for harmonic current emissions (equipment input current $<=16 \mathrm{~A}$ per phase), 2005.

[8] IEC 61000-4-13: Electromagnetic compatibility (EMC) - Part 4-13: Testing and measurement techniques - Harmonics and interharmonics including mains signalling at a.c. power port, low frequency immunity tests, 2009.

[9] G. Rietveld, C. Kramer, E. Houtzager, O. Kristensen, D. Zhao, C. de Leffe, and T. Lippert, "Characterisation of a wideband digitiser for power measurements up to $1 \mathrm{MHz}$, IEEE Trans. Instr. Meas., vol. 60, pp. $2195-2201,2011$.

[10] K. Lind, T. Sørsdal, and H. Slinde, "Design, modeling, and verification of high-performance AC-DC current shunts from inexpensive components", IEEE Trans. Instr. Meas., vol. 57, no. 1, pp. 176-181, Jan. 2008.

[11] NEN-EN 50470-3 Electricity metering equipment (a.c.) - Part 3: Particular requirements - Static meters for active energy (class indexes A, B and C), 2009. 